\title{
A COMPARATIVE STUDY BETWEEN CHARACTERISTICS SEEN IN SUPERVISED VERSUS NON-SUPERVISED EMPLOYEES
}

\author{
Dr. Cedric Thomas Silveira $1 \square$ \\ ${ }^{1}$ Assistant Professor, Don Bosco College, Panaji, Goa 403001, India.
}

Received 15 September 2021

Accepted 15 October 2021

Published 31 October 2021

\section{CorrespondingAuthor}

Dr. Cedric Thomas Silveira, cedricsilveira@yahoo.com

DOI

10.29121/granthaalayah.v9.i10.2021 4342

Funding: This research received no specific grant from any funding agency in the public, commercial, or not-for-profit sectors.

Copyright: (C) 2021 The Author(s). This is an open access article distributed under the terms of the Creative Commons Attribution License, which permits unrestricted use, distribution, and reproduction in any medium, provided the original author and source are credited.

\section{ABSTRACT}

Supervised and unsupervised employees are assumed to be quite different. A supervised employee can always fall back to the supervisor in times of need as compared to an unsupervised employee who has to fend for himself in most times. Wishing to find out as to what keeps supervised as well as unsupervised employees going in an organization, I drew up a questionnaire to be filled up by the employees. The questionnaire had six variables which had to be ranked from 1 to 6 , with 1 being the most important and 6 being the least important. The variables were Discipline, Growth, Desire to learn, Organizational skills, Dedication, and Motivation. A total of 100 employees were interviewed, 50 who were supervised and 50 who were not supervised. A personal interview was conducted wherein the questionnaire was direct and structured. The results were such among the supervised employee's growth was ranked first followed by discipline and desire to learn whereas among the unsupervised employee's growth was ranked first followed by desire to learn and motivation.

Keywords: Growth, Discipline, Dedication, Motivation, Organization Skills

\section{INTRODUCTION}

Are supervised and unsupervised employees different in their way of thinking? Do they have different needs or are they similar in their needs and desires Wishing to learn more about this issue, I interviewed 50 supervised and 50 unsupervised employees of companies. I presented them with a questionnaire which they had to rank six variables, namely discipline, growth, desire to learn, organizational skills, dedication, and motivation.

Discipline is essential for any worker. Without discipline he or she will not be able to function well. Discipline begins with being punctual to work, ready to obey orders from the supervisor and do the work on time.

Growth is something that all employees desire, in a supervised or unsupervised setting. Growth, development and prosperity are variables that most employees want from their company or work place setting. If growth is not there in a company usually the employees will leave the company and go to another company where the growth prospects are healthier than the current company.

Desire to learn is usually seen among unsupervised employees as they have no one to guide them and as a result will often go beyond their work schedule in search of more information. In today's world of new technology, one has to be constantly updated with the latest in order to survive competition and grow. 
Organizational skills are required by all employees as they plan, schedule and implement their day-to-day work. Good organizational skills are usually learnt faster when one is left on his own as through experience and trial and error one will be able to succeed.

Dedication was yet another variable selected as dedication is important to get the work finished on time. An undedicated employee will try to waste his time, dilly dally and procrastinate. A dedicated employee will be focused till the job is complete.

Motivation is something that keeps one going. A motivated individual is also a productive individual. Motivation will be high if the employee knows what and why he is doing something, gets feedback and rewards for his work and is given opportunity to work by himself and take his own decisions. In a supervised setting usually, the supervisor will take the decisions and although he may consult the employees, the final decision is taken by him only.

The ranking was then analyzed using Thurstone Case $\mathrm{V}$ scaling technique wherein each variable was compared with another variable. The results were then searched from the Thurstone Case V scaling table and the final values were plotted on a unidimensional scale. Variables which supervised employees considered important were compared with unsupervised employees to find out if any difference existed between the two

\section{LITERATURE REVIEW}

The literature review was conducted to find out the important characteristics of supervised and unsupervised employees in a work setting.

According to Costen and Salazar (2011) training and development play an important role in the growth of the employee. Not only does the employee derive job satisfaction and loyalty, but also, he feels that his growth prospects in the organization will improve and his intent to stay on in the organization improves.

Oldham and Cummings (2017) feel that creativity and challenging jobs can be undertaken if employees are supervised in a supportive non controlled fashion. This means that a lot of discipline is required from the employees to work alongside with the supervisor at the workplace.

Mastekaasa and Oslen (1998) on the other hand feel that unsupervised employees especially ladies lack discipline when it comes to working. According to them women stay absent 1.3 to 1.7 times more as compared to men. However, the reason which they give is that health conditions or personality differences exist between the two genders.

Rooney et al. (2009) have a different perspective to dedication among employees. They feel that supervised employees have a greater sense of dedication and loyalty to the organization as compared to unsupervised employees. The study was conducted on 34 employees across different ranks and positions. Dedication and belongingness were seen to a greater extent among supervised employees.

And finally, Burke and Miller (1999) are of the opinion that taking decisions is become vital in today's world. Motivation is higher among those who can take a decision which in turn means that unsupervised employees will be motivated to a larger extend. 60 experienced professionals were interviewed and their views were found out. Their decision making was what kept them motivated. 


\section{OBJECTIVE}

1) To find out which characteristics were considered important by supervised employees when compared with unsupervised employees

\section{RESEARCH DESIGN}

A random, direct, structured questionnaire was utilized wherein a personal interview was conducted on 100 employees, 50 supervised and 50 unsupervised, in companies across Goa. The research design was of an exploratory design.

\section{FINDINGS}

The Thurstone Case V Scaling was used to analyze the data in the supervised employees. The comparison between the variables was first made wherein the variables A, B, C, D, E and F were compared with each other. A-Discipline B- Growth C- Desire to learn D - Organizational skills E- Dedication and F- Motivation.

1 represents most Preferred and 5 least Preferred

\begin{tabular}{ccccccc} 
& A & B & C & D & E & F \\
\hline A & 0.5 & $31 / 50$ & $25 / 50$ & $10 / 50$ & $13 / 50$ & $12 / 50$ \\
B & $19 / 50$ & 0.5 & $18 / 50$ & $5 / 50$ & $15 / 50$ & $14 / 50$ \\
C & $25 / 50$ & $32 / 50$ & 0.5 & $12 / 50$ & $17 / 50$ & $15 / 50$ \\
D & $40 / 50$ & $45 / 50$ & $38 / 50$ & 0.5 & $33 / 50$ & $34 / 50$ \\
E & $37 / 50$ & $35 / 50$ & $33 / 50$ & $17 / 50$ & 0.5 & $19 / 50$ \\
F & $38 / 50$ & $36 / 50$ & $35 / 50$ & $16 / 50$ & $31 / 50$ & 0.5
\end{tabular}

Converting to decimals, we get

\begin{tabular}{ccccccc}
\hline & A & B & C & D & E & F \\
\hline A & 0.5 & 0.62 & 0.5 & 0.2 & 0.26 & 0.24 \\
B & 0.38 & 0.5 & 0.36 & 0.1 & 0.3 & 0.28 \\
C & 0.5 & 0.64 & 0.5 & 0.24 & 0.34 & 0.29 \\
D & 0.8 & 0.9 & 0.76 & 0.5 & 0.66 & 0.68 \\
E & 0.74 & 0.7 & 0.66 & 0.34 & 0.5 & 0.39 \\
F & 0.76 & 0.72 & 0.71 & 0.32 & 0.61 & 0.5 \\
\hline
\end{tabular}

Finding the values from the Thurstone Case V scaling table, we get

\begin{tabular}{ccccccc}
\hline & A & B & C & D & E & F \\
\hline A & 0 & 0.29 & -0.03 & -0.84 & -0.66 & -0.72 \\
B & -0.28 & 0 & -0.35 & -1.23 & -0.44 & -0.6 \\
\hline C & 0.03 & 0.35 & 0 & -0.72 & -0.4 & -0.55 \\
D & 0.84 & 1.23 & 0.72 & 0 & 0.43 & 0.47 \\
\hline E & 0.66 & 0.44 & 0.4 & -0.43 & 0 & -0.25 \\
F & 0.72 & 0.6 & 0.55 & -0.47 & 0.25 & 0 \\
\hline
\end{tabular}


Adding the values of each variable we get

\begin{tabular}{cccccc}
\hline A & B & C & D & E & F \\
\hline 1.97 & 2.91 & 1.29 & -3.69 & -0.82 & -1.65
\end{tabular}

Adding the least value which is 3.69 to all the variables we get

\begin{tabular}{cccccc}
\hline A & B & C & D & E & F \\
\hline 5.66 & 6.6 & 4.98 & 0 & 2.87 & 2.04
\end{tabular}

The Thurstone Case V Scaling was used to analyze the data in the unsupervised employees. The comparison between the variables was first made wherein the variables A, B, C, D, and E were compared with each other. A- Price of the brand BQuality of the brand C-Safety of the brand D-New Products E- Brand Name FFrequency of dosing.

1 represents most Preferred and 5 least Preferred

\begin{tabular}{ccccccc} 
& A & B & C & D & E & F \\
\hline A & 0.5 & $41 / 50$ & $36 / 50$ & $23 / 50$ & $24 / 50$ & $29 / 50$ \\
B & $9 / 50$ & 0.5 & $14 / 50$ & $8 / 50$ & $7 / 50$ & $8 / 50$ \\
\hline C & $14 / 50$ & $36 / 50$ & 0.5 & $9 / 50$ & $6 / 50$ & $9 / 50$ \\
D & $27 / 50$ & $42 / 50$ & $41 / 50$ & 0.5 & $21 / 50$ & $27 / 50$ \\
E & $26 / 50$ & $43 / 50$ & $44 / 50$ & $29 / 50$ & 0.5 & $22 / 50$ \\
F & $21 / 50$ & $42 / 50$ & $41 / 50$ & $23 / 50$ & $28 / 50$ & 0.5 \\
\hline
\end{tabular}

Converting to decimals, we get

\begin{tabular}{ccccccc}
\hline & A & B & C & D & E & F \\
\hline A & 0.5 & 0.82 & 0.72 & 0.46 & 0.47 & 0.58 \\
B & 0.18 & 0.5 & 0.28 & 0.16 & 0.14 & 0.16 \\
\hline C & 0.28 & 0.72 & 0.5 & 0.18 & 0.12 & 0.18 \\
D & 0.54 & 0.84 & 0.82 & 0.5 & 0.42 & 0.54 \\
\hline E & 0.53 & 0.86 & 0.88 & 0.58 & 0.5 & 0.44 \\
F & 0.42 & 0.84 & 0.82 & 0.46 & 0.56 & 0.5 \\
\hline
\end{tabular}

Finding the values from the Thurstone Case V scaling table, we get

\begin{tabular}{ccccccc}
\hline & A & B & C & D & E & F \\
\hline A & 0 & 0.92 & 0.61 & -0.1 & -0.08 & 0.18 \\
B & -0.92 & 0 & -0.54 & -1.01 & -1.06 & -0.97 \\
\hline C & -0.61 & 0.54 & 0 & -0.9 & -1.2 & -0.9 \\
D & 0.1 & 1.02 & 0.9 & 0 & -0.18 & 0.09 \\
\hline E & 0.8 & 1.06 & 1.2 & 0.18 & 0 & 0.16 \\
F & -0.18 & 0.97 & 0.9 & 0.09 & 0.16 & 0 \\
\hline
\end{tabular}

Adding the values of each variable we get

\begin{tabular}{llllll}
\hline A & B & C & D & E & F \\
\hline-1.53 & 4.51 & 3.07 & -1.74 & -2.36 & -1.44
\end{tabular}


Adding the least value which is -2.36 to all the variables we get

\begin{tabular}{llllll}
\hline A & B & C & D & E & F \\
\hline 0.83 & 6.87 & 5.43 & 0.62 & 0 & 0.92
\end{tabular}

\section{CONCLUSIONS}

1) In the supervised category growth was ranked first, followed by discipline, desire to learn, dedication, motivation and organizational skills. Growth was evident, and discipline is essential in a supervised setting. Motivation and organizational skills are ranked low because probably in a supervised setting the employees do not get the opportunity to take decisions on their own or are spoon fed. Their organizational skills are also ranked low because their supervisor may be doing all the planning and scheduling.

2) In the unsupervised category growth was also ranked number one followed by desire to learn, motivation, discipline, organizational skills and dedication. Desire to learn and motivation are ranked high because both are variables which represent taking decisions by oneself and being independent. Discipline, dedication is ranked low perhaps because unsupervised employees feel independent and do not remain focused on completing the job in a specific period of time.

3) If the first 3 variables are compared there is a small difference between the two,that is supervised and unsupervised employees. If growth is number 1 in both, discipline followed by desire to learn is seen in supervised employees as compared to desire to learn and motivation in unsupervised employees.

\section{LIMITATIONS OF THE STUDY}

1) The study was conducted on 50 supervised employees and 50 unsupervised employees. As some questionnaires were found to be incomplete or wrongly filled up, they were discarded and new employees were selected.

2) Some other tools and techniques could have been used. However, Thurstone Case V scaling was found to be sufficient.

\section{SUGGESTIONS}

A year later the same study can be conducted and the results can be compared for consistency.

\section{REFERENCES}

Burke, L.A., Miller, M.K. (1999). Taking the mystery out of intuition in Decision making. Academy of Management Perspectives, Vol (13), Issue 4. Retrieved from https: / /doi.org/10.5465/ame.1999.2570557

Costen, W., Salazar,J. (2011). Impact of training and development on employee job satisfaction, loyalty and intent to stay in the lodging industry. Journal of Human Resources in Hospitality and Tourism, Vol (10), Issue 2. Retrieved from https://doi.org/10.1080/15332845.2011.555734

Donald cooper, Pamela S. (2006), " Business Research Methods", Tata Mc Graw Hill, N. Delhi 
Mastekaasa, A., Oslen, K.M. (1998). Gender, Absenteeism and Job related characteristics : A fixed effects approach. Work and Occupations. Retrieved from https://doi.org/10.1177/0730888498025002004

Oldham, G.R., Cummings, A. (2017). Employee creativity : Personal and Contextual Factors at work, Academy of Management Journal, Vol (39), Issue 3. Retrieved from https://doi.org/10.2307/256657

Paul E Green, Donald S Tull, (1990), " Research for Marketing Decisions", Prentice Hall Int, INC, N. Delhi.

Rooney., Paulsen, N., Callan, V.J. (2009). A new role for place identity in managing organizational change. Management Communication Quaterly. Retrieved from https://doi.org/10.1037/t34905-000 